\title{
O Programa de Cidades Históricas, o turismo e a "viabilidade econômica" do patrimônio (1973-1979)
}

\section{Leila Bianchi Aguiar ${ }^{1}$}

RESUMO: Criado pela Secretaria de Planejamento da Presidência da República (Seplan), no ano de 1973, o Programa de Revitalização das Cidades Históricas (PCH) tinha como meta principal a preservação e o desenvolvimento econômico de alguns dos conjuntos urbanos brasileiros patrimonializados. As ações desenvolvidas por esse programa serão aqui analisadas como parte de um fenômeno mais amplo da história da preservação do patrimônio cultural brasileiro, o estímulo à transformação dos sítios preservados em atrações turísticas. Para tanto, foram analisados documentos, palestras e discursos de personagens fundamentais para as atividades de salvaguarda do patrimônio e de promoção do turismo, além de periódicos e legislação do período.

PALAVRAS-CHAVE: Programa de Cidades Históricas. Patrimônio Cultural. Turismo. Instituto do Patrimônio Histórico e Artístico Nacional. Cidades Históricas.

ABSTRACT: Created by the President's Office of Planning (Seplan) in 1973, the Program for the Revitalization of historical cities (PCH) had as its main goal the preservation and the economical development of some of Brazil's heritage urban complexes. The actions carried out by this program will be analyzed here as part of a broader phenomenon in the history of Brazilian cultural heritage preservation, namely an encouragement to transform preserved sites into tourist attractions. In order to do so, I analyze documents, lectures, and speeches delivered by some of the essential players in the activities of heritage preservation and the promotion tourism, in addition to periodicals and legislation from the time period.

KEYWORDS: Historical Cities Program. Cultural Heritage. Tourism. National Historical and Artistic Heritage Institute. Historical Cities.

\begin{abstract}
1. Professora Adjunta do Departamento de História e do Programa de Pósgraduação em História da Universidade Federal do Estado do Rio de Janeiro. E-mail: <leila.aguiar@ unirio.br>
\end{abstract}


2. Optamos por chamar de Iphan a agência federal de preservação, criada como Serviço do Patrimônio Histórico e Artístico Nacional (SPHAN) em 1937. Em 2 de janeiro de 1946, o Decreto-1ei 8534 transformou o SPHAN em diretoria. A agência responsável pelo patrimônio histórico e artístico brasileiro passou então a chamar-se DPHAN. Em 27 de julho de 1970, o Decreto n. 66.967 transformou a DPHAN em instituto - Iphan. Em 26 de novembro de 1979, o Congresso Nacional aprovou a Lei n. 6.757, criando a Fundação Nacional Pró-Memória, que se tornou um órgão operacional do Iphan. Um resumo cronológico com as principais transformações sofridas por essa agência pode ser encontrado em SPHAN resumo cronológico (1987, p. 34).

3. Ver Leila Bianchi Aguiar (2014a, 2014b).

4. Diretor da Instituição entre 1937 e 1966. O Guia de Ouro Preto, de autoria de Manuel Bandeira foi publicado no ano de 1938. Ver Manuel Bandeira (1963).

5. No ano de 1927 , foram criadas as primeiras companhias aéreas em território brasileiro: a Viação Rio-Grandense S.A e o Sindicato Condor. Já no ano de 1947, o Brasil liderava a aviação comercial na América Latina e, entre os anos de 1969 a 1973, o transporte comercial do país teve um crescimento médio anual de $20 \%$. Ver Luiz Gonzaga Trigo (2000).

6. Nos anos 60, o Brasil possuía uma taxa de urbanização de 44,7\%. Em 1980, 67,6\% do total da população já vivia em cidades. Cf. www.ibge.gov. br.
Organização, regulamentação e consolidação da atividade turística no Brasil

Desde os primeiros anos de funcionamento do Instituto do Patrimônio Histórico e Artístico Nacional (Iphan)², observam-se ações que visavam ao desenvolvimento turístico dos conjuntos urbanos preservados, conforme analisamos em trabalhos anteriores ${ }^{3}$. Apesar das dificuldades de acesso, da distância de muitas das "cidades históricas" dos grandes centros e da incipiente organização do mercado turístico no Brasil, o lphan apoiou a construção de hotéis, a abertura de museus e a publicação de guias com informações turísticas desde 1938. Em Ouro Preto, cidade que se tornaria um dos maiores símbolos da preservação do patrimônio cultural no Brasil, discussões sobre a necessidade de atrair e orientar os visitantes estão presentes em documentos produzidos pela instituição durante o projeto e a construção do Grande Hotel, projetado por Oscar Niemeyer, quando da transformação da antiga Casa de Câmara e Cadeia em Museu da Inconfidência, e com a publicação do Guia de Ouro Preto, escrito por Manuel Bandeira a convite do Iphan a partir de informações fornecidas, principalmente, por Rodrigo Melo Franco de Andrade 4 .

Naquele momento, a atividade turística no Brasil carecia de organização, embora já contasse com agências que buscavam estimulá-la, sendo possível destacar o papel do Touring Clube do Brasil. A partir das legislações de férias elaboradas na década de 1930, parte dos trabalhadores urbanos passou a dispor de tempo livre que se ampliou para alguns grupos profissionais, como consequência de movimentos sindicais e da afirmação de uma visão que passou a relacionar férias e maior rendimento no trabalho. A expansão do turismo internacional após o fim da segunda guerra mundial, a abertura das rodovias em grande parte do território brasileiro, o desenvolvimento dos transportes aéreos comerciais $^{5}$ e o aumento da urbanização com a absorção de mão de obra das zonas rurais ${ }^{6}$ são elementos que nos permitem compreender os novos rumos do turismo brasileiro a partir de fins da década de 1960.

No ano de 1966, foi implantado o Sistema Nacional de Turismo com a criação do Conselho Nacional de Turismo CNTur e a Empresa Brasileira de Turismo (Embratur), com o objetivo de desenvolver políticas de incentivo ao setor. As agências recém-criadas deveriam auxiliar o governo a melhorar a imagem do país no exterior, abalada pelo golpe militar e pelas violências cometidas a partir de então ${ }^{7}$. Nesse período, observamos a consolidação de um mercado de bens culturais no Brasil. Nas palavras de Renato Ortiz:

Estado Autoritário permite consolidar no Brasil o Capitalismo Tardio. Em termos culturais essa reorientação econômica traz consequências imediatas pois, paralelamente ao crescimento do parque industrial e do mercado interno de bens materiais, fortalece-se o parque industrial de produção de cultura e o mercado de bens culturais ${ }^{8}$.

Novas formas de organização do setor turístico se desenvolveram com a expansão de grandes empreendimentos de hospedagem e transporte aéreo 
internacional e a difusão da padronização de pacotes de viagem por grandes operadoras de turismo. A nova agência estatal tornou-se a mais importante reguladora e organizadora de políticas públicas para o turismo por conter em seus quadros importantes nomes da iniciativa privada nos ramos hoteleiro, da aviação civil e das agências turísticas?.

Apesar de textos como o documento final da Reunião do Sistema Nacional de Turismo, de 1977, assegurarem a existência de uma clara separação entre as funções do poder público e da iniciativa privada, tal divisão, na prática, não ocorria, uma vez que a Embratur e o CNTur eram espaços privilegiados de atuação para o empresariado do setor turístico no interior do Estado brasileiro. A política em prol do desenvolvimento turístico apresentava-se como uma necessidade nacional no discurso oficial. Para além de regulamentar as atividades turísticas, os órgãos federais de turismo foram responsáveis pelas políticas de financiamento e subsídio da área. Destacamos aqui as isenções fiscais concedidas a hotéis em construção até o ano de 1971, que poderiam atingir até 50\% de desconto, e a criação de fundos que poderiam ser utilizados no desenvolvimento da atividade, como o Fundo Geral de Turismo (Fungetur) nesse mesmo ano e o Fundo de Investimento Setorial de Turismo (FISET), em 1974, com verbas provenientes de dotações da União e da Embratur ${ }^{10}$. A partir de então, tornou-se possível a concessão de empréstimos a juros baixos e incentivos fiscais para a construção de hotéis instalados em determinadas regiões do Brasil, mais especificamente, no Norte e no Nordeste.

\section{$\bigcirc$ Programa de Cidades Históricas e o turismo}

A expansão mundial do turismo gerou grandes reflexos para o campo da preservação a partir da década de 1960. Conforme verificamos no relatório elaborado no ano de 1968 por Michel Parent ${ }^{11}$, consultor que esteve no país financiado pela Unesco em 1966 e 1967, a conservação dos bens culturais brasileiros, até então subsidiada pelo governo, deveria, integrar os projetos de desenvolvimento nacional ${ }^{12}$. Dentre eles, o turismo, com altos índices de crescimento anuais, destacava-se como um setor altamente promissor.

A defesa do turismo enquanto uma importante via para o desenvolvimento econômico e para a "auto-sustentabilidade" ou geração de recursos para a preservação do patrimônio cultural resume a argumentação principal da Unesco nos documentos produzidos por essa agência a partir de fins da segunda metade da década de 1960. Mesmo com uma breve advertência de que o turismo de massa poderia contribuir para a degradação dos bens culturais brasileiros ${ }^{13}$, o sedutor argumento de que essa atividade financiaria as urgentes obras de restauração dos bens imóveis e conjuntos urbanos patrimonializados captando recursos da iniciativa privada e não somente do Estado foi amplamente utilizado ao longo das 128 páginas do relatório da Unesco de 1968, segundo o qual essa era uma tendência entre os países europeus mais desenvolvidos. Nesse novo contexto, os bens deveriam ser preservados porque eram atrações turísticas e,
7. Ver Joaquim Xavier da Silveira (1977).

8. Cf. Renato Ortiz (1988).

9. Ver Leila Bianchi Aguiar (2010) .

10. Ver palestra realizada por Joaquim Xavier da Silveira, presidente da Embratur, em Ouro Preto, em 20/06/1969. Arquivo Central do IPHAN Subsérie Congresso. Caixa 88 pasta 81. Ver Decreto-Lei n. 1.191 , de 27/10/1971 (reorganizado pelo art. 13 do Decreto-Lei n. 1.439, de $30 / 12 / 1975$, e ratificado pelo art. 59 da Consolidação das Leis de Turismo).

11. Ver Michel Parent (1968).

12. Ibidem (p. 1).

13. Ibidem. 
14. A opção de utilizar turismo cultural entre aspas se deve a uma crítica à forma como comumente o termo é utilizado, principalmente para os gestores da atividade turística, muitas vezes para marcar um tipo de turismo que se distinguiria, radicalmente, do turismo tradicional porque inclui a visitação a museus e centros históricos; o que nos leva também a questionar a possibilidade de realização de um turismo não cultural somente porque não inclui a visitação a museus $\mathrm{e}$ conjuntos patrimonializados. Consideramos a classificação muito mais como um subproduto, originado do desenvolvimento da atividade turística que ao especializar-se atinge distintos nichos do mercado, sendo cada vez mais comum as classificações como turismo ecológico, turismo de aventura..etc.

15. Ver Michel Parent (1968, p. 11).

16. Ibid. (p.24-25).

17. Ver Unesco (1969, p.35).

18. Ver Embratur (1972).

19. Ibid. (p.3).

20. Ibid. consequentemente, capacitavam-se novos agentes sociais aptos a defini-los, geri-los e desenvolver novas formas de salvaguarda.

De acordo com esse documento, a condição excepcional do Brasil para - "turismo cultural"14 era consequência direta de sua diversidade cultural, da existência de sítios urbanos preservados e também de sua "aptidão à modernidade". Esta última poderia ser comprovada pela arquitetura moderna presente em cidades como Brasília, o que facilitaria a construção de equipamentos turísticos ${ }^{15}$. Após enumerar os benefícios do desenvolvimento turístico brasileiro, o relatório de Michel Parent analisa o potencial de algumas das regiões do país e lista algumas das medidas necessárias para seu aproveitamento. Dentre elas, destaca-se o estímulo à aviação comercial, ao transporte marítimo e fluvial e à construção de novas rodovias e ferrovias ${ }^{16}$.

Apesar da argumentação favorável ao turismo nos sítios urbanos preservados, podemos notar no relatório de Parent para a Unesco uma preocupação constante em mostrar que essa não era a posição dessa agência internacional, mas o necessário para salvaguardar a cultura dos diversos povos do planeta naquele momento. A "escassez de recursos públicos" ou o alto custo da preservação do patrimônio edificado exigia, principalmente dos países mais pobres, a busca por alternativas para a conservação dos patrimônios culturais. $\bigcirc$ crescimento do turismo cultural seria igualmente responsável por facilitar o acesso aos bens preservados para o "grande público". Para os especialistas da Unesco, a indústria turística brasileira até esse momento era pouco organizada e "o Brasil não estava verdadeiramente consciente desse setor de atividade, o qual é o que se desenvolve mais rapidamente no plano internacional, constituindo, portanto, uma fonte de divisas para os países" ${ }^{\prime 17}$

A defesa efetuada pela Unesco da expansão do turismo para os sítios urbanos brasileiros preservados como solução para sua conservação coincidia com o desenvolvimento mundial dessa atividade e com a consequente exigência de criação de novos destinos turísticos. $\bigcirc$ "turismo cultural", cada vez mais realizado nas antigas cidades europeias, poderia crescer expressivamente no Brasil, constataram representantes das associações empresariais do setor de transporte, hospedagem e agências de viagens durante a Reunião Oficial de Turismo ${ }^{18}$, realizada no ano de 1972, na qual enfatizaram a necessidade de "tornar possível o aproveitamento de pontos turísticos ainda inexplorados" e "utilizar métodos de ensinamentos práticos no aproveitamento e divulgação dos encantos naturais, culturais e históricos" ${ }^{19}$. Para tanto, seria necessário associar às viagens a sítios urbanos preservados, museus e outras atrações do gênero, um novo status, capaz de consagrá-los como espaços que deveriam, obrigatoriamente, ser conhecidos. Em um documento produzido a partir da Reunião Oficial de Turismo, encontramos uma passagem exemplar nesse sentido.

Há ainda a intenção de despertar nas pessoas um certo sentimento de culpa, ou mesmo de vergonha, pelo fato de não conhecerem certos lugares e coisas que vezes por outra são citados nas conversas, inclusive as sofisticadas. É, pois uma alfinetada na vaidade humana ${ }^{20}$. 
A preocupação com a entrada de divisas tornou-se maior em função das sucessivas crises do petróleo, nos anos de 1973 e 1979, durante as quais se observou uma diminuição da entrada de moedas estrangeiras por meio dos constantes empréstimos realizados ao governo brasileiro. A defesa do desenvolvimento turístico como atividade geradora de recursos para a balança comercial assumiria um papel de destaque nos anos seguintes, durante os quais se tornou crucial a "entrada de dólares" para a manutenção do modelo econômico baseado no capital internacional21.

A primeira ação conjunta entre a Embratur e o lphan ocorreu no ano de 1973, quando foi criado o Programa Integrado de Reconstrução das Cidades Históricas do Nordeste que visava, prioritariamente, a "conservação e a restauração do acervo cultural para uma utilização economicamente viável"22. Para tanto, priorizou a recuperação de monumentos existentes em núcleos possuidores de infraestrutura turística ou em suas áreas de influência, e, no interior desses espaços, os monumentos em vias de destruição ${ }^{23}$. A restauração de bens culturais em áreas com potencialidades para o turismo seria uma forma de atrair investimentos e valorizar pequenas cidades ou mesmo bairros de grandes cidades até então marginais dentro do processo de acumulação capitalista brasileiro, então com grandes índices de crescimento, o "Milagre brasileiro", seguindo também as recomendações da Conferência de Quito.

Programa foi criado pela Secretaria de Planejamento da Presidência da República (Seplan), dirigida pelo ministro João Paulo dos Reis Velloso, após a transformação do Ministério do Planejamento em uma secretaria diretamente ligada à presidência e responsável pela elaboração do II Plano Nacional de Desenvolvimento (1975-79) que buscou, ao longo do governo Geisel, dar prosseguimento às medidas desenvolvimentistas em uma tentativa de recuperar a economia brasileira que não atingia os mesmos índices de crescimento, em um momento que ficou conhecido como crise do milagre.

Também dava prosseguimento às políticas públicas, implementadas com maior eficácia desde a criação da Sudene em 1957, reforçando uma das principais preocupações expressas no IPND, ou seja, minimizar as grandes disparidades dos níveis de renda do Nordeste e do Centro-Sul. Por essa razão, inicialmente, voltavase apenas para as cidades históricas do Nordeste. Em debate na sede da Sudene, em Recife, no dia 17 de Julho de 1974, o Ministro do Interior, Maurício Rangel Reis, declarava que o crescimento do restante do Brasil havia sido superior ao do Nordeste e que se quisessem equacioná-lo, essa região teria que crescer no mínimo $12,5 \%$ e, para tanto, seriam necessários grandes investimentos federais ${ }^{24}$.

$\bigcirc$ programa tinha como meta principal a preservação e o desenvolvimento econômico de alguns conjuntos urbanos preservados que, de acordo com as avaliações realizadas por órgãos como Embratur, Sudene, Iphan, pudessem oferecer retornos financeiros aos investimentos realizados ou mesmo se tornassem rentáveis, conforme podemos verificar nos documentos referentes à valorização dos núcleos urbanos de Icó e Aracati no Ceará ${ }^{25}$.
21. Ver Paul Singer (1976); Francisco de Oliveira (1977).

22. Ver Augusto Carlos da Silva Telles (s.d.).

23. Ver Exposição de motivos 076-B de 31 de maio de 1973 dos ministros do planejamento e da Educação e Cultura citada por Augusto Carlos da Silva Telles no documento Planos Regionais e definição de prioridades para o programa integrado de reconstrução das cidades históricas do Nordeste. Mimeo. Arquivo Central do Iphan. Caixa 79M69P1Pasta 31.08.

24. Ver Sudene reivindica crescimento de $12,5 \%$ ao ano. Jornal do Brasil. Rio de Janeiro, p. 22, 17 jul. 1974..

25. Ver Exposição de motivos 076-B de 31 de maio de 1973 dos ministros do planejamento e da Educação e Cultura citada por Augusto Carlos da Silva Telles no documento Planos Regionais e definição de prioridades para o programa integrado de reconstrução das cidades 
históricas do Nordeste. Mimeo. Arquivo Central do Iphan. Caixa 79M69P1Pasta 31.08 .

26. Idem.

27. Cf. Exposição de motivos 076-B de 31 de maio de 1973 dos ministros do planejamento e da Educação e Cultura citada por Augusto Carlos da Silva Telles no documento Planos Regionais e definição de prioridades para o programa integrado de reconstrução das cidades históricas do Nordeste, p.2. Mimeo. Arquivo Central do Iphan. Caixa 79M69P1Pasta 31.08.

28. Ver Sandra Rafaela Magalhães Corrêa (2012).

29. Ver Carta Internacional sobre Conservação e Restauração de Monumentos e Sítios (1964).

30. BRASIL. Lei número 6513, de 20 de dezembro de 1977.

31. BRASIL. Lei número 6513, de 20 de dezembro de 1977.p. 167.
Os investimentos de capitais para a execução dos projetos de valorização do patrimônio monumental devem ser feitos simultaneamente com os que reclamam o equipamento turístico da zona ou região objeto de revalorização ${ }^{26}$.

Cada estado envolvido deveria apresentar um projeto indicando monumentos a serem preservados e os roteiros turísticos a serem divulgados. Para a liberação das verbas para a revitalização dos patrimônios culturais, seria avaliada a viabilidade do desenvolvimento do turismo nos conjuntos urbanos preservados, principalmente em relação aos acessos rodoviários e distância das grandes capitais. Dessa forma, a "viabilidade econômica", algumas vezes apresentada como "função útil à sociedade" ou "interesse comunitário"27, tornava-se uma prioridade para o programa que reunia as principais verbas que seriam destinadas à preservação do patrimônio cultural nacional.

No entanto, de acordo com Sandra Corrêa ${ }^{28}$, em muitos casos as influências políticas prevaleciam na definição de obras e projetos a serem desenvolvidos nos monumentos e núcleos preservados, a partir de acordos firmados entre os governos estaduais e a administração federal, desrespeitando as prioridades enunciadas. Além disso, as intervenções focavam-se, principalmente, nos monumentos e não nos sítios históricos, o que vinha de encontro às normas internacionais seguidas desde a Carta de Veneza, assinada em $1964^{29}$

O crescimento do turismo nos sítios urbanos brasileiros preservados foi tão significativo que, no ano de 1977, de acordo com a Lei n. 6513, de 20 de dezembro desse ano, os imóveis, conjuntos urbanos e bens naturais preservados foram também classificados como áreas especiais de interesse turístico, nos seguintes termos:

Art. 1o. Consideram-se de interesse turístico as Áreas Especiais e os Locais instituídos na forma da presente Lei, assim como os bens de valor cultural e natural, protegidos por legislação específica, e especialmente:

1-Os bens de valor histórico, artístico, arqueológico ou pré-históricol... $)^{30}$.

A partir de tal definição, os sítios urbanos preservados, assim como reservas e estações ecológicas, fontes hidrominerais, localidades com condições climáticas excepcionais e outras áreas de especial interesse turístico estariam "destinados por sua adequação ao desenvolvimento de atividades turísticas, e à realização de projetos específicos"31 por intermédio da Embratur, do Iphan e de agências como o Instituto Brasileiro de Desenvolvimento Florestal (IBDF) e a Secretaria Especial de Meio-Ambiente (SEMA). A preservação dos bens culturais e naturais, enfatizada ao longo dessa legislação, justificava-se a partir do momento em que eles foram classificados como áreas especiais de interesse turístico.

Com a Lei n.6.513, de 1977, a preservação dos bens culturais brasileiros estaria legalmente atrelada à sua potencialidade enquanto atrativo turístico - uma mudança significativa em relação às legislações específicas sobre a preservação 
cultural, mais especificamente, em relação ao Decreto-lei n. 25, de 1937. No contexto da criação desse decreto-lei, a construção de narrativas sobre a nação, por meio da eleição de lugares de memória a serem preservados, constituía um projeto mais poderoso que o aproveitamento lucrativo dos conjuntos urbanos.

$\mathrm{Na}$ legislação de 1977, foram consideradas "áreas especiais de interesse turístico prioritárias" as que apresentavam maior facilidade de acesso ou mesmo potencial turístico. Dessa forma, os investimentos estariam atrelados à existência de fluxos de turistas e, consequentemente, os "projetos específicos" preservação dos bens culturais estariam subordinados à lógica de desenvolvimento do turismo. $\bigcirc$ artigo 12 da Lei n. 6.513 definia como áreas prioritárias

(...) áreas de alta potencialidade turística, que devam ou possam ser objeto de planos e programas de desenvolvimento turístico, em virtude de :

a) ocorrência ou iminência de expressivos fluxos de turistas e visitantes;

b) existência de infra-estrutura turística e urbana satisfatória, ou possibilidade de sua implementação;

c) necessidade da realização de planos e projetos de preservação ou recuperação dos locais de interesse turístico nelas incluídos;

d) realização presente ou iminente de obras públicas ou privadas, que permitam ou assegurem o acesso à área, ou a criação da infra-estrutura mencionada na alínea "b";

e) conveniência de prevenir ou corrigir eventuais distorções do uso do solo, causadas pela realização presente ou eminente de obras públicas ou privadas, ou pelo parcelamento e ocupação do solo.

Com tais critérios para a definição de áreas prioritárias para novos investimentos, a legislação de 1977 regulamentava uma prática frequente dos órgãos oficiais de planejamento e turismo em relação às áreas preservadas, desde 1975, com o Programa Cidades Históricas. Nesse programa, as obras de conservação e recuperação dos conjuntos urbanos preservados estariam subordinadas às possibilidades de desenvolvimento turístico da região onde se localizavam ${ }^{33}$.

Em 1977, ocorreu a extensão do PCH para as cidades dos estados do Rio de Janeiro, Espírito Santo e Minas Gerais. Na Carta do Turismo Cultural do Icomos, escrita em 1977, a expansão do turismo para os sítios urbanos foi defendida e estimulada:

Cultural tourism is that form of tourism whose object is, among other aims, the discovery of monuments and sites. It exerts on these last a very positive effect insofar as it contributes - to satisfy its own ends - to their maintenance and protection. This form of tourism justifies in fact the efforts which said maintenance and protection demand of the human community because of the socio-cultural and economic benefits which they bestow on all the populations concerned ${ }^{34}$.

Dessa forma, podemos observar, durante as décadas de 1960 e 1970, frequentes estudos, normas, recomendações e encontros organizados pelas principais agências internacionais ligadas à preservação de bens culturais, em defesa do desenvolvimento do "turismo cultural" nos conjuntos urbanos.
32. Ibid..

33. Ver Augusto Carlos da Silva Telles (s.d.).

34. Turismo cultural é aquela forma de turismo cujo objeto é, dentre outros propósitos, a descoberta de monumentos e sítios, o que exerce nestes em última instância um efeito muito positivo, assim como contribui - para satisfazer seus próprios fins- para sua manutenção e proteção. Essa forma de turismo justifica, de fato, os esforços que sua manutenção e proteção demandam da comunidade humana devido aos benefícios socioculturais e econômicos que eles trazem para todas as populações envolvidas. (tradução nossa) Disponível em: <http://www.icomos. org/tourism/tourism charter.html>, acesso em 13 jan. 2003.. 
35. Ver Maria Cecília Londres Fonseca (2005, p.154).

36. Cf. CPI do Patrimônio (1979, p.3)

37. Ibid.
Em 1979, Aloísio Magalhães, que havia sido responsável pela elaboração de uma metodologia em prol da utilização de elementos de comunicação visual no turismo, foi nomeado diretor do Iphan, e ocorreu a fusão desse instituto com o Centro Nacional de Referências Culturais (CNRC) e o PCH. O principal objetivo com essas medidas era reforçar a agência de preservação com o objetivo de criar maior flexibilidade para suas ações e descentralizar a administração federal. Em $O$ patrimônio em processo, obra que se tornou uma referência para a trajetória das políiticas de preservação no Brasil, Maria Cecília Londres analisa essa união da seguinte forma "reuniam-se assim, numa só instituição os recursos e o know-how gerencial do PCH, o prestígio e a competência técnica do Iphan e a visão moderna e renovadora do $\mathrm{CNRC}^{\prime \prime 35}$.

Nos boletins do Sphan pró-memória publicados desde então, Aloísio Magalhães destacava o papel do programa de cidades históricas na descentralização do Iphan. A ampliação do conceito de patrimônio foi amplamente defendida, desde princípios da década de 1970, quando foram criados organismos de preservação cultural nos âmbitos municipal e estadual, após a realização do Encontro de Governadores, e o PCH, à época no interior da Seplan. O principal argumento utilizado era o da necessidade de aproximação das comunidades locais a seus bens culturais.

Veio pelo filão econômico, em parte, a ideia de que, se revitalizarmos certas áreas do Nordeste, a nível de seu valor econômico, nós poderíamos ter maior turismo, fluxo de interesse etc. Então, nasceu esse programa com verbas específicas do Fundo Nacional de Desenvolvimento - portanto, não do MEC, mas da SEPLAN. Esse programa tem realizado um trabalho extraordinário nesses oito anos de existência, porque, na verdade, ele inaugurou dentro do sistema antigo do IPHAN a descentralização ${ }^{36}$.

De acordo com a última passagem transcrita do depoimento de Aloísio Magalhães à CPI do patrimônio, a descentralização do Iphan seria uma consequência das transformações econômicas, advindas, principalmente, da expansão do turismo para as áreas preservadas, e não somente uma mudança no interior da instituição em prol de uma maior participação das comunidades locais, conforme indicam discursos pronunciados por intelectuais da área, e até mesmo parte da bibliografia sobre a política preservacionista brasileira que costuma associar a nova gestão de Aloísio Magalhães no Iphan a uma maior democratização do patrimônio, sem efetuar análises sobre o "filão econômico", segundo expressão do autor.

Nas palavras de Aloísio Magalhães, "Quem está próximo do bem cultural, quem está ligado ao bem cultural é, verdadeiramente, quem deve cultiváto. De forma que essa descentralização é absolutamente fundamental" ${ }^{\prime 37}$. De fato, observa-se durante a execução do programa a criação de órgãos e secretarias, nos âmbitos municipal e estadual, responsáveis pela preservação de seus bens culturais, condição necessária para que os estados e municípios contemplados recebessem as verbas do programa. Embora esse fenômeno ocorresse em menor escala, desde o ano de 1970, ano do primeiro Encontro de Governadores em Braśília sobre o assunto, o 
programa ampliou o número de órgãos oficiais de salvaguarda, passo importante para o processo de descentralização das políticas de patrimônio.

Além de elaborar uma linguagem própria para a identificação de atrações turísticas, Aloísio Magalhães esforçava-se, ainda, em definir o turismo como um bem cultural, seguindo a longa tradição que, sistematicamente, negava a definição de turismo enquanto um ramo da atividade industrial, uma das muitas formas encontradas para a construção de um consenso em torno dos benefícios do turismo pelos intelectuais das agências que visavam promoção dessa atividade. Aloísio afirmava que:

Preliminarmente, eu diria que me coloco entre os que não consideram o turismo propriamente como um produto. Eu acho que há uma tendência em se tomar um bem cultural, de grande significado numa comunidade, por um ângulo apenas desse problema, que é o ângulo mercadológico e transformando, portanto, em produto $(\ldots)^{38}$.

Iphan passou a receber dotações anuais desse programa, sofrendo novas influências na realização de suas atividades de salvaguarda do patrimônio cultural brasileiro. As ações que deveriam ser executadas no interior do PCH para "proteção por meio da legislação adequada da paisagem e de outros motivos considerados como atração turística" apresentavam semelhanças com o modelo de salvaguarda do patrimônio histórico e artístico nacional brasileiro, coordenado pelo Sphan desde sua criação, em 1937. No entanto, podemos verificar que termos como "patrimônio cultural" e "patrimônio natural", largamente utilizados no campo da preservação cultural, passaram a ser tratados nas legislações e regimentos do setor turístico como sinônimos de "patrimônio turístico"39, uma prática iniciada em 1958 com a criação da Combratur, e que se tornou mais frequente com o desenvolvimento do turismo nos sítios urbanos preservados.

Outro marco no processo aqui analisado foi a criação do Inventário da Oferta Turística e a Identificação do Espaço Turístico, no ano de 1979. De acordo com a Embratur, o inventário possibilitaria a produção de "instrumentos para as atividades de planejamento turístico em nível nacional, regional, municipal e local com vistas à proteção, preservação e divulgação da oferta turística", enquanto a identificação propiciaria a definição de "municípios e espaços turísticos necessários a uma política de descentralização e estabelecimento de novos núcleos de apoio à expansão turística, além de disciplinar a ocupação territorial visando a preservação e divulgação da oferta turística" 40 . Caberia ainda à Embratur, de acordo com a nova legislação e, em conjunto com tais órgãos e entidades, definir os bens culturais e naturais protegidos que poderiam ser utilizados turisticamente, e as formas pelas quais eles poderiam apresentar atividades econômicas compatíveis com a sua preservação ${ }^{41}$.

A Embratur e outros órgãos oficiais de turismo brasileiros iniciaram o Inventário da Oferta Turística e a Identificação do Espaço Turístico tendo como base os inventários de identificação dos bens culturais desenvolvidos pelo lphan desde sua criação. Ao analisarmos o projeto de identificação de "espaços turísticos"42, verificamos que seguia à risca as indicações do Centro de Capacitação Turística (Cicatur) ligado à OEA, organização sob forte influência norte-americana, que
38. Cf. CPI do Patrimônio (1979, p. 1-4).

39. BRASIL. Decreto $n$. 48.126 de 19 de abril de 1960.

40. Cf. Maria das Graças Paiva (1995).

41. BRASIL. Lei n. 6513, de 20 de dezembro de 1977. Art. $60 \$ 1$.

42. Cf. Embratur (1979). 
43. Idem (p.79).

44. Ver Aloísio Magalhães (1982).

45. Cf. Conselho de Turismo apoia programa de Praia Grande (1980, p.17).

46. Seria interessante assinalar que antes de tornar-se presidente do Iphan, Aloísio Magalhães já havia realizado projetos para a Embratur, sendo responsável pela criação de símbolos de sinalização turística.

47. Cf. Conselho de Turismo apoia programa de Praia Grande (1980, p.17). também havia organizado a conferência sobre preservação cultural, em Quito, no ano de 1967, na qual foram aprovadas normas para a utilização comercial do patrimônio cultural. O novo inventário buscava selecionar ou inventariar os atrativos turísticos da região visando o maior aproveitamento dessas áreas.

Nesse projeto, além da "seleção de espaços turísticos", buscava-se disciplinar a ocupação territorial "visando a preservação do patrimônio turístico nacional"43. Mais uma vez, o termo "patrimônio turístico" substituía o conceito de patrimônio cultural ou mesmo de patrimônio histórico e artístico nacional. Tal mudança sinalizava uma distinta concepção não só sobre a definição dos bens culturais preservados, mas, principalmente, de sua utilização. A função deixou de ser exclusivamente a de monumento ou mesmo de lugar de memória ou documento e os patrimônios culturais transformaram-se também em valorizadas matérias-primas para a indústria do turismo.

Ao identificar tais espaços, a Embratur assumiu um papel fundamental na atribuição de valores aos bens incluídos ou excluídos na classificação de "patrimônio turístico nacional".

apoio ao desenvolvimento turístico também seria justificado tendo, muitas vezes, por base novas concepções sobre as políticas de patrimônio, desde fins da década de 1970, cujo objetivo principal deveria ser uma maior integração com as comunidades locais, principalmente, a partir da criação do CNRC, um novo órgão que teria alterado os rumos da política cultural brasileira ${ }^{44}$. A proposta de democratização do patrimônio que vem à tona nesse momento, frequentemente era associada ao desenvolvimento turístico dos espaços preservados.

Já os organismos de turismo, além de participar da atribuição de valores, tiveram uma crescente presença nas discussões envolvendo a preservação cultural nos sítios urbanos. As possibilidades de financiamento de programas de conservação, em um período em que o Iphan passou a dispor de escassas verbas, aumentaram a importância e a consequente participação de instituições como a Embratur e o CNTur nas políticas públicas direcionadas aos conjuntos urbanos. A título de exemplo, poderíamos destacar matéria publicada no Boletim do IPHAN, em 1980, afirmando que o CNTur aprovou a proposta apresentada pelo Iphan de revitalização da Praia Grande, em São Luís do Maranhão, e que a Embratur iria alocar recursos do Fundo Geral de Turismo para apoiar o programa ${ }^{45}$. Referindo-se a tais investimentos, Aloísio Magalhães ${ }^{46}$, então presidente do Iphan definiu o turismo como:

(...) fenômeno de comunicação inerente ao homem, profundo desejo de conhecer o outro, de entrar em contato com outras realizações, de ser participante, tanto quanto possível, da realidade do seu próximo e, como tal, o turismo transcende no sentido de conter um coeficiente de uma importância enorme que é esse fenômeno de comunicação humana ${ }^{47}$.

Essas participações eram consideradas fundamentais para evitar a ruína e a destruição total de alguns dos mais importantes conjuntos urbanos tombados pela instituição. Nesse quadro mais amplo de construção de um consenso sobre a necessidade do desenvolvimento do turismo no Brasil, mesmo agentes ligados à 
preservação do patrimônio reiteraram análises sobre a atividade turística que classificaram como ação "inerente aos seres humanos", realizada de forma desinteressada, desconsiderando-se muitas vezes o contexto histórico-social mais amplo no qual ela se insere. Tal argumentação fortaleceu-se, principalmente, em países como o Brasil, nos quais os financiamentos estatais mostravam-se insuficientes para os investimentos necessários para a manutenção da integralidade do patrimônio cultural nacional. A alternativa do "turismo cultural" aparecia como solução para os problemas relativos à preservação do patrimônio cultural brasileiro

Considerações finais

Programa de Revitalização das Cidades Históricas foi a primeira grande tentativa de inclusão dos sítios urbanos patrimonializados nos processos de acumulação e geração de renda. A visão favorável ao desenvolvimento turístico nas cidades históricas foi externada por intelectuais de destaque no campo da preservação, como Aloísio Magalhães, que caracterizaram a atividade turística como vetor de integração das comunidades locais e de democratização do patrimônio.

A defesa do turismo como atividade fundamental para os sítios urbanos preservados por ser geradora de recursos e empregos faz parte de um quadro mais amplo de produção de um consenso sobre a importância de impulsionar essa atividade, envolvendo diversos agentes e instituições brasileiras e internacionais. Presente nos discursos e propostas políticas, o turismo foi apresentado como atividade capaz de erguer a economia brasileira e retirar do atraso e da estagnação em que se encontravam muitos dos municípios brasileiros - o "toque de midas" que traria prosperidade para os locais onde se instalaria, oferecendo uma possibilidade de "recuperação" dos espaços preservados.

Durante todo o período de acentuado crescimento do fluxo turístico, essa atividade foi apresentada pelas agências federais criadas para desenvolvê-lo e regulamentá-lo, como uma necessidade para o desenvolvimento nacional. Dentre as justificativas apresentadas, a geração de divisas e o equilíbrio da balança comercial com a entrada de turistas estrangeiros e seus consequentes gastos no Brasil foram as mais frequentes, sempre acompanhadas de críticas à ausência de investimentos por parte do governo federal nessa área. $\bigcirc$ turismo também foi associado à melhoria das condições de vida das populações por ele afetadas e ao desenvolvimento econômico das regiões e países que investiram nesse setor produtivo.

Organizações como a Unesco, lcomos, OEA e o Cicatur tornavam-se decisivas, não somente na elaboração de normas e metodologias a serem seguidas pela Embratur, mas ainda na formação de técnicos e primeiros graduados na área de turismo 48 . Esses profissionais se tornaram alguns dos principais "intelectuais orgânicos" desse novo campo que se afirmava no Brasil, desempenhando um papel fundamental na formação de um consenso sobre a importância do turismo para o desenvolvimento da economia do país e na geração de renda para sua população.
48. Ver Maria das Graças Paiva (1995, p. 56). 


\section{REFERÊNCIAS}

\section{FONTES PRIMÁRIAS}

Arquivo Central do Iphan, Rio de Janeiro

EMBRATUR. Política Nacional de Turismo, 1972. mimeo.

Palestra realizada por Joaquim Xavier da Silveira, presidente da Embratur em Ouro Preto em 20/06/1969. mimeo. Subsérie Congresso. Caixa 88 pasta 81.

PARENT. Michel. Protection et mise em valeur du patrimoine culturel brésilien dans le cadre du développement par M. Parent. Paris: Unesco, mars, 1968. mimeo.

Sudene reivindica crescimento de 12,5\% ao ano. Jornal do Brasil. Rio de Janeiro, p. 22, 17 jul. 1974.

TELLES, Augusto Carlos da Silva. Planos Regionais e definição de prioridades para o programa integrado de reconstrução das cidades históricas do Nordeste. Mimeo. Caixa 79M69P1Pasta 31.08

UNESCO. Conservation de quartiers anciens et développemént touristique à Salvador. Paris, 1969. mimeo.

\section{LEGISLAÇÃO E CARTAS INTERNACIONAIS}

BRASIL. Lei n. 6513, de 20 de dezembro de 1977.

BRASIL. Decreto n. 48.126, de 19 de abril de 1960.

BRASIL. Decreto-Lei n. 1.191, de 27 de outubro de 1971 (reorganizado pelo art. 13 do Decreto-Lei n. 1.439, de 30 de dezembro de 1975, e ratificado pelo art. 59 da Consolidação das Leis de Turismo).

CARTA Internacional sobre Conservação e Restauração de Monumentos e Sítios, aprovada em maio de 1964, durante o II Congresso Internacional de Arquitetos e Técnicos dos Monumentos Históricos - ICOMOS. Disponível em: <http://portal.iphan.gov.br/uploads/ckfinder/arquivos/ Carta\%20de\%20Veneza\%201964.pdf>. Acesso em 28 abr. 2016.

\section{LIVROS, ARTIGOS, TESES E PUBLICAÇÕES EM GERAL}

AGUIAR, Leila Bianchi. Estado, turismo, cultura e desenvolvimento: organização empresarial e a construção do consenso sobre a importância do turismo para o Brasil. In: Anais do VI Simpósio Nacional Estado e Poder, 2010, São Cristóvão-SE. Universidade Federal de Sergipe, 2010.

Projetos nacionais de preservação do patrimônio: promoção, divulgação e turismo nos sítios urbanos patrimonializados durante a gestão de Rodrigo Mello Franco de Andrade. In: MAGALHÃES, Aline Montenegro; BEZERRA, Rafael Zamorano. (Org.). 90 anos do Museu Histórico Nacional. Rio de Janeiro: Museu Histórico Nacional, 2014, p. 186-194. 
AGUIAR, Leila Bianchi; CHUVA, Márcia. Institucionalização das práticas de preservação do patrimônio cultural no Brasil e na Argentina e suas relações com as atividades turísticas. Antíteses, Londrina, v.7, p.68-93, 2014.

BANDEIRA, Manuel. Guia de Ouro Preto. Rio de Janeiro: Letras e Artes, 1963.

CONSELHO de Turismo apoia programa de Praia Grande. Boletim IPHAN, Brasília. n.5, p. 17, mar.-abr.1980.

CORRÊA, Sandra Rafaela Magalhães. O Programa de Cidades Históricas (PCH): por uma política integrada de preservação do patrimônio cultural - 1973/1979. 2012. Dissertação (Mestrado em Arquitetura e Urbanismo) - Universidade de Brasília, Brasília, 2012.

CPI do Patrimônio. Boletim SPHAN/pró-Memória, Brasília, n. 2, .p. 1-4, set.-out. 1979.

EMBRATUR. Identificação do espaço turístico nacional. Rio de Janeiro: Embratur, 1979.

FONSECA, Maria Cecília Londres. O patrimônio em processo: trajetória da política federal de preservação no Brasil. 2. ed. Rio de Janeiro: UFRJ/Iphan, 2005.

MAGALHÃES, Aloísio. O papel do patrimônio cultural no futuro da nação.Boletim SPHAN/ pró-Memória, Brasília, n. 17, p. 13-14, mar.-abr.1982.

OLIVEIRA, Francisco de. A economia da dependência imperfeita. Rio de Janeiro: Graal, 1977.

ORTIZ, Renato. A moderna tradição brasileira: cultura brasileira e indústria cultural. São Paulo: Brasiliense, 1988.

PAIVA, Maria das Graças Menezes. Sociologia do turismo. Campinas: Papirus, 1995.

SILVEIRA, Joaquim Xavier da. Turismo: prioridade nacional. Rio de Janeiro: Record, 1977.

SINGER, Paul. A crise do milagre. Rio de Janeiro: Paz e Terra, 1976.

SPHAN - resumo cronológico. Revista do Patrimônio Histórico e Artístico Nacional, Brasília, n. 22, p. 34, 1987.

TRIGO, Luiz Gonzaga Godoi. Viagem na memória: guia histórico das viagens e do turismo no Brasil. São Paulo: Senac, 2000. 